\title{
Mycobacterial antigens in pleural fluid mononuclear cells to diagnose pleural tuberculosis in HIV co-infected patients
}

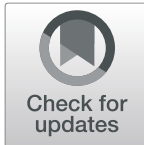

Tehmina Mustafa ${ }^{1,2^{*}+}$, Ida Wergeland ${ }^{3+}$, Kamaldeen Baba ${ }^{4,5}$, Sharad Pathak ${ }^{6}$, Anwar A. Hoosen ${ }^{4,7}$ and Anne Margarita Dyrhol-Riise $8,9,10$

\begin{abstract}
Background: Extra pulmonary manifestation of tuberculosis (TB) accounts for approximately one-half of TB cases in HIVinfected individuals with pleural TB as the second most common location. Even though mycobacteria are cleared, mycobacterial antigens may persist in infected tissues, causing sustained inflammation and chronicity of the disease. The aim of this study was to explore various mycobacterial antigens in pleural effusions, the impact of HIV infection and CD4+ T-cell depletion on the presence of antigens, and the diagnostic potential of antigens for improved and rapid diagnosis of pleural TB.

Methods: Pleural fluid specimens were collected from patients presenting with clinically suspected pleural TB, and processed routinely for culture, cytology, and adenosine deaminase activity analysis. HIV status and CD4+ T-cell counts were recorded. Pleural fluid mononuclear cells (PFMC) were isolated, and cell smears were stained with acid-fast staining and immunocytochemistry for various mycobacterial antigens. Real-time and nested-PCR were performed. Patients were categorized as pleural TB or non-TB cases using a composite reference standard. Performance of the mycobacterial antigens as diagnostic test was assessed.

Results: A total of 41 patients were enrolled, of which 32 were classified as pleural TB and 9 as non-TB. Thirteen patients had culture confirmed pleural TB, 26 (81\%) were HIV-TB co-infected, and 64\% had < 100 CD4+ T-cells/microL. Both secreted and cell-wall mycobacterial antigens were detected in PFMC. Lipoarabinomannan (LAM) was the most frequently detected antigen. There was no direct correlation between positive culture and antigens. Cases with low CD4+ T-cell counts had higher bacterial and antigen burden. By combining detection of secreted antigen or LAM, the sensitivity and specificity to diagnose pleural TB was 56 and 78\%, respectively, as compared to 41 and 100\% for culture, 53 and 89\% for nested PCR, and 6 and 100\% for realtime PCR.
\end{abstract}

Conclusion: Mycobacterial antigens were detectable in PFMC from tuberculous pleural effusions, even in cases where viable mycobacteria or bacterial DNA were not always detected. Thus, a combination of secreted antigen and LAM detection by immunocytochemistry may be a complement to acid-fast staining and contribute to rapid and accurate diagnosis of pleural TB.

Keywords: Mycobacterial antigens, LAM, MPT64, Pleural fluid mononuclear cells, Diagnosis, Pleural tuberculosis, HIV-TB coinfection

\footnotetext{
* Correspondence: Tehmina.mustafa@uib.no

${ }^{\dagger}$ Tehmina Mustafa and Ida Wergeland contributed equally to this work.

${ }^{1}$ Centre for International Health, Department of Global Public Health and

Primary Care, University of Bergen, P.O. box 7804, N-5020 Bergen, Norway

${ }^{2}$ Department of Thoracic Medicine, Haukeland University Hospital, Bergen,

Norway

Full list of author information is available at the end of the article
}

C C The Author(s). 2020 Open Access This article is licensed under a Creative Commons Attribution 4.0 International License, which permits use, sharing, adaptation, distribution and reproduction in any medium or format, as long as you give appropriate credit to the original author(s) and the source, provide a link to the Creative Commons licence, and indicate if changes were made. The images or other third party material in this article are included in the article's Creative Commons licence, unless indicated otherwise in a credit line to the material. If material is not included in the article's Creative Commons licence and your intended use is not permitted by statutory regulation or exceeds the permitted use, you will need to obtain permission directly from the copyright holder. To view a copy of this licence, visit http://creativecommons.org/licenses/by/4.0/ The Creative Commons Public Domain Dedication waiver (http://creativecommons.org/publicdomain/zero/1.0/) applies to the data made available in this article, unless otherwise stated in a credit line to the data. 


\section{Background}

On a global scale, tuberculosis (TB) is a leading cause of death from a single infectious agent. In 2018, 10 million people were estimated to have developed TB disease, and 1.2 million died because of TB. TB remains the number one cause of death in people living with HIV [1]. In South Africa, $60 \%$ of adult TB cases are HIV positive [1]. Extrapulmonary $\mathrm{TB}$ accounts for approximately one-fifth of $\mathrm{TB}$ cases in immune-competent individuals and up to onehalf in HIV-infected individuals [2, 3]. In high TB endemic settings, TB of the pleura occurs in up to $30 \%$ of TB patients, the second most common site of extrapulmonary involvement following lymph node TB [4]. In the HIVinfected population, pleural TB is the most common cause of a lymphocytic pleural effusion [4-6].

The natural history of TB pleural effusion in HIVnegative individuals is a slow resolution without treatment, although, up to $65 \%$ will progress to active TB within 5 years $[7,8]$. However, with HIV-coinfection, progression to active disease is more frequent and occurs faster. TB pleural effusions, most probably occur as a result of pleural infection directly from associated parenchymal lesions [9-11]. Immunocompetent individuals are able to mount a strong immune response, and are thus able to control mycobacterial multiplication [12], resulting in paucibacillary forms of TB disease [13]. Paradoxically, the immune response of the host is also responsible for the pathology and chronicity of the disease. It is believed that, even though mycobacteria are cleared, mycobacterial antigens persist in the infected tissue and could be responsible for persistent inflammation and chronicity of disease [14-17].

The pathogenesis of pleural TB in HIV co-infected TB cases is not fully understood. Little is known about the impact of HIV and depletion of CD4+ T-cells on the pathogenesis of pleural TB, or the identity of the mycobacterial antigens persisting in TB pleural effusions.

Studies have shown that people with TB and HIV coinfection with low CD4+ T-cell counts have detectable Lipoarabinomannan (LAM) in urine [18]. This implies that HIV-induced CD4+ T-cell depletion affects the ability of the host to control mycobacterial replication, thereby, leading to higher bacillary load and disseminated disease with higher amounts of mycobacterial antigens at the disease site.

We have previously shown that the expression of mycobacterial antigens in pulmonary TB is distinct from that of extrapulmonary TB [17]. Of note, we have specifically demonstrated that the secreted mycobacterial antigen MPT64 is preferentially expressed in and co-localized with TB lesions, leading to the hypothesis that this protein is accumulated in inflammatory cells and could be responsible for persistence of disease [17, 19-25]. The detection of secreted mycobacterial antigen MPT64 by immunochemistry from the aspirates, effusions or biopsies has been evaluated as a useful and better diagnostic test for various forms of extrapulmonary TB [17, 19-25].

The aim of this study was to explore the expression of various mycobacterial antigens in the cells from pleural effusions, the impact of HIV infection and CD4 + T-cell depletion on the accumulation of mycobacterial antigens, and the diagnostic potential of mycobacterial antigens from pleural effusion for improved and rapid diagnosis of pleural TB.

\section{Methods \\ Study participants}

Pleural fluid analyses were performed on stored samples from a previous published study [26]. Briefly, patients presenting with pleural effusion and clinical symptoms of pleural TB admitted to the Dr. George Mukhari Hospital, Ga-Rankuwa, Pretoria, South Africa during the period 20042005 were recruited into the study. Patients with recent TB therapy ( $<1$ year) or treated with corticosteroids, immunosuppressive or antiretroviral therapy were not included. HIV testing was done routinely in pleural effusion patients with suspected TB. The demographic and clinical data, HIV status and CD4+ T-cell count were recorded for each patient.

\section{Specimen collection and processing}

Thoracocentesis was performed according to clinical practice at the hospital. The pleural fluid specimens were processed according to standard laboratory routines for acid fast bacilli (AFB) staining of smears and culture (BacT-alert, Org anon, Teknika). The pleural fluid was also sent for cytological examination and Adenosine deaminase activity (ADA) analysis using a commercial colorimetric assay kit (Diazyme General Atomics, CA) with a cut-off value for positive test of 30 $\mathrm{U} / \mathrm{L}[27,28]$. At the time of inclusion pleural fluid mononuclear cells (PFMCs) were isolated from approximately $200 \mathrm{ml}$ pleural fluid by density gradient centrifugation (Ficoll histopaque 1077, Sigma). Cells were washed once with isotonic $\mathrm{NaCl}$, and twice with $\mathrm{RPMI}$ with $10 \%$ fetal calf serum (FCS) (1640, L-glutamine and HEPES supl., Sigma), and resuspended in RPMI media to make a final concentration of $1 \times 10^{6}$ cells $/ \mathrm{ml}$. Cells were cryopreserved in 10\%DMSO/90\%FCS. Cryovials were placed in $-80^{\circ} \mathrm{C}$, and then transferred into liquid nitrogen for long term storage. The cells were shipped to Haukeland University Hospital, Bergen, Norway for further analysis. Cryovials were thawed in a $37^{\circ} \mathrm{C}$ water bath until the cell suspension was almost melted. The cell suspension was then transferred to $5 \mathrm{~mL}$ centrifuge tubes containing RPMI with $10 \%$ FCS at $37^{\circ} \mathrm{C}$, centrifuged at $350 \mathrm{~g}$ for $5 \mathrm{~min}$, and resuspended in RPMI with $10 \%$ FCS. Smears were made for Ziehl Neelsen staining and immunocytochemical staining. 


\section{Immunocytochemical staining}

All antibodies used in the study were in-house rabbit polyclonal, except for anti-Bacille Calmette- Gu rin (BCG), which was obtained from DAKO Immunoglobulins, Copenhagen, Denmark (code B124; lot 063B). Table 1 shows the immunogens used for production of these antibodies, target antigens, how they are named in the manuscript, and dilutions. The specificity of these antisera has been determined by earlier studies $[21,29]$.

Immunocytochemistry was performed by using the DakoCytomation kit (EnVision + System-HRP; DakoCytomation Denmark A/S, Glostrup, Denmark). The PFMC smears were passed through graded alcohol and treated with $3 \%$ bovine serum albumin for $5 \mathrm{~min}$. Primary antibodies were added, and the smears incubated for $1 \mathrm{~h} 15$ min. Optimal dilutions were determined by titration. The smears were incubated with anti-rabbit dextran polymer conjugated to horseradish peroxidase for $45 \mathrm{~min}$. The endogenous peroxidase activity was inhibited by incubating the smears with hydrogen peroxide for $8 \mathrm{~min}$. Antigens were visualized by incubation with 3-amino-9-ethylcarbazol and hydrogen peroxide containing substrate for 15 min. The smears were counter-stained with hematoxylin. All incubations were carried out at room temperature and the smears were washed thoroughly between incubations.

Negative and positive controls were included in all experiments. One smear where the primary antibody was substituted with antibody diluent, and one smear from a patient with non-tuberculous pleural effusion were used as negative controls. One smear from a culture positive patient with abundant acid-fast bacilli on Ziehl-Neelsen staining was used as positive control.

\section{Evaluation of immunostaining}

The stained slides were evaluated at 10x magnification using a light microscope and positive signals were further assessed at 40x magnification. Cells with intracellular granular staining were counted at 10x magnification. The whole smear was examined, and the number of fields counted. The antigen load was quantified by calculating the number of stained cells per 100 fields. For diagnostic purpose, a case with any positive signal was labelled as positive.

\section{Nested polymerase chain reaction (PCR) for IS6110}

DNA extraction was performed by adding $400-1000 \mu \mathrm{L}$ of the PFMC suspension to a cryotube containing $250 \mu \mathrm{l}$ of acid-washed micro-glass beads and ribolysing the tubes for $45 \mathrm{~s}$. A 123- base pair fragment from IS6110 was amplified using the following primers 5' CCTGCG AGCGTAGGCGTCGG $3^{\prime}$ and $5^{\prime}$ CTCGTCCAGC GCCGCTTCGG 3'. The product was subjected to a second round of PCR amplification using the primers $5^{\prime}$ TTCGGACCACCAGCACCTAA $3^{\prime}$ and $5^{\prime}$ TCGGTG ACAAAGGCCACGTA $3^{\prime}$ to amplify a 92-base pair fragment. The PCR reaction mixture consisted of $5 \mu \mathrm{L}$ DNA, $25 \mu \mathrm{L}$ Taq master mix (Qiagen), $0.25 \mu \mathrm{l}$ of each $100 \mu \mathrm{M}$ primer stock solution, and distilled water to make a final volume of $50 \mu \mathrm{l}$. For the second round of PCR, $1 \mu \mathrm{L}$ of the first PCR product was used as template. The reaction cycle for the first PCR was- $94{ }^{\circ} \mathrm{C}$ for 1 min, $68^{\circ} \mathrm{C}$ for $1 \mathrm{~min}, 72^{\circ} \mathrm{C}$ for $20 \mathrm{~s}$ for 45 cycles, and for the nested-PCR $-94{ }^{\circ} \mathrm{C}$ for $1 \mathrm{~min}, 58^{\circ} \mathrm{C}$ for $1 \mathrm{~min}$, and $72{ }^{\circ} \mathrm{C}$ for $20 \mathrm{~s}$ for 35 cycles. Both PCR had an initial heat activation step of $95^{\circ} \mathrm{C}$ for $15 \mathrm{~min}$ and a final extension of $72{ }^{\circ} \mathrm{C}$ for $10 \mathrm{~min}$. The amplified products were analyzed in a $3 \%$ agarose gel stained with ethidium bromide. Mycobacterial DNA isolated from bacterial cultures was used as positive control and a reaction tube where test template was substituted with distilled water as negative control in each PCR run. A negative control tube

Table 1 Primary polyclonal antibodies, immunogens used for the production of antibodies, target antigens, the name used in the study, and dilutions used for immunohistochemistry

\begin{tabular}{|c|c|c|c|c|}
\hline Antibody & Immunogen & Target antigens & Study name & Dilution \\
\hline Anti-MPT64 & $\begin{array}{l}\text { Antigen extracted and purified from the } 5 \text { weeks old } \\
\text { culture filtrate of } M \text {. tuberculosis with minimal lysis. } \\
\text { The term MPT was introduced by Nagai et al. for the } \\
\text { designation of proteins purified from M.tuberculosis. } \\
\text { The number is based on their relative mobility in } \\
7.7 \% \text { polyacrylamide gel electrophoresis gels at a } \\
\text { running pH of } 9.5 \text { [29]. }\end{array}$ & $\begin{array}{l}\text { MPT64 (Rv1980c). Secreted antigen specific } \\
\text { for M.tuberculosis complex organisms. } \\
\text { Absent from most of atypical mycobacteria. }\end{array}$ & $\begin{array}{l}\text { secreted } \\
\text { antigen }\end{array}$ & $1: 50$ \\
\hline Anti-Antigen 60 & $\begin{array}{l}\text { Cell wall antigens of M.tuberculosis. The number is } \\
\text { based on their relative mobility as mentioned above } \\
\text { [29] }\end{array}$ & Major M.tuberculosis cell wall antigens. & $\begin{array}{l}\text { Cell wall } \\
\text { antigens }\end{array}$ & $1: 100$ \\
\hline $\begin{array}{l}\text { Anti- } \\
\text { Lipoarabinomannan } \\
\text { (LAM) }\end{array}$ & LAM & $\begin{array}{l}\text { LAM, the primary component of } \\
\text { M.tuberculosis cell wall. }\end{array}$ & LAM & $1: 100$ \\
\hline $\begin{array}{l}\text { Anti-Bacille } \\
\text { Calmette- Gue'rin } \\
\text { (BCG) }\end{array}$ & $\begin{array}{l}\text { Bacterial sonicates of BCG containing both secreted } \\
\text { and cell wall antigens. }\end{array}$ & $\begin{array}{l}\text { Most of the secreted and cell wall antigens } \\
\text { of the } M \text {. tuberculosis based on the similarity } \\
\text { between M.tuberculosis and BCG. }\end{array}$ & $\begin{array}{l}\text { Heterogeneous } \\
\text { antigens }\end{array}$ & 1:2000 \\
\hline
\end{tabular}


containing RPMI, going through all steps including the DNA extraction protocol were also included.

Mycobacterial DNA load was estimated based on the number of nested-PCR positive triplicates from each sample. Low and high load was defined when PCR was positive in one of the three, and three of three samples, respectively. For diagnostic purposes, any positive in the triplicate was labelled as positive. The gel electrophoresis image of the nested-PCR results for some of the samples is shown in Fig. 1.

\section{Real-time PCR}

A real-time PCR assay targeting a 103-base pair long segment of the mycobacterial heat shock protein 65 gene GroEL2 was performed as previously published by our group [30]. The target segment was amplified using the forward primer MycoFP1 (5' -CGAGGCGATGGACA AGGT-3'), the reverse primer TB12 (5' -CTTGTC GAACCGCATACCCT-3'), and the fluorescent-tagged Taq Man MGB probe MycoPr1 (5' -VIC-AACGAG GGCGTCATCACCGTCG-MGB-3'). The PCR reactions were set up in a total volume of $20 \mu \mathrm{l}$ consisting of $10 \mu \mathrm{L}$ of $2 \times$ TaqMan Universal PCR MasterMix (Applied Biosystems), $5 \mu \mathrm{L}$ DNA extract from clinical specimen and a final concentration of each primer and probe of $0.9 \mu \mathrm{M}$ and $0.25 \mu \mathrm{M}$, respectively. Amplification was done with a 7500 Fast-Real-Time System (Applied Biosystems) using the following parameters: $2 \mathrm{~min}$ at $50^{\circ} \mathrm{C}$ to activate AMPErase UNG, $10 \mathrm{~min}$ at $95^{\circ} \mathrm{C}$ to activate AmpliTaq Gold, followed by 45 thermal cycles of $95^{\circ} \mathrm{C}$ for $15 \mathrm{~s}$ and $60^{\circ} \mathrm{C}$ for $1 \mathrm{~min}$. Each clinical specimen was run in technical duplicates or triplicates. To further ensure the reliability of results, each run included both negative controls ( $5 \mu \mathrm{L}$ of sterile water) as well as several positive controls (known dilutions of genomic DNA from Bacille Calmette- Gue'rin, Mycobacterium spp. ATCC 19015D). Standard quantification curves were generated based on the known concentrations of the positive controls using the Sequence Detection System software v1.3 (Applied Biosystems). As per recommendations of the manufacturer (Applied Biosystems), realtime PCR data were analyzed using a threshold set at 10 SDs above background signal level and only threshold cycle values below 40 were noted as positive.

\section{Patient categories}

The patients were categorized by using a composite reference standard by combining the clinical and laboratory diagnostic criteria. Pleural TB was defined based on either mycobacterial confirmation by AFB microscopy and/or culture positive pleural fluid, or in the absence of bacteriological confirmation by clinical criteria based on $\mathrm{ADA} \geq 30 \mathrm{U} / \mathrm{L}$ from the pleural fluid and/or strong clinical evidence consistent with active $\mathrm{TB}$ followed by a

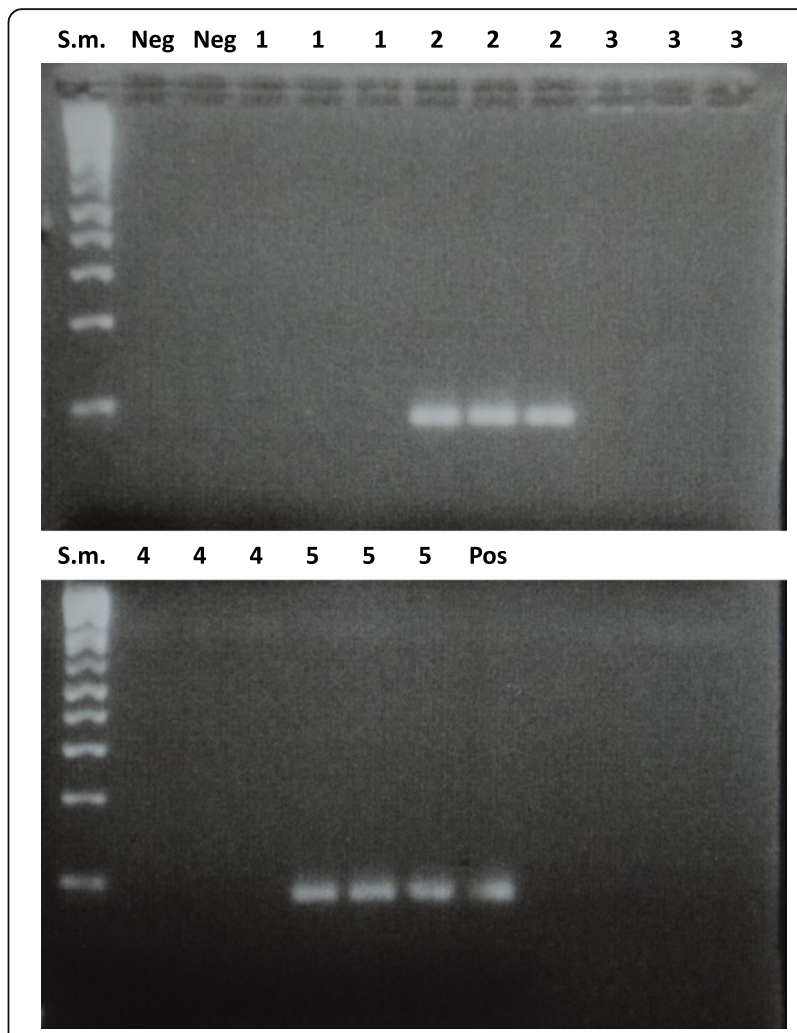

Fig. 1 Gel electrophoresis of the nested-PCR showing PCR amplification of a 92-bp fragment of IS6110. Results of five samples are shown, with triplicates from each sample. Only sample 2 and 5 are positive. Lane s.m.; size marker. Neg; negative control. Pos; positive control

clinical decision to treat with anti-tuberculosis therapy [26]. A case was categorized as non-TB when diagnosed as malignancy or another non-TB condition.

\section{Statistical analysis}

Data was analyzed using Statistical Package for the Social Sciences for Windows version 25.0. The data was not normally distributed, thus non-parametric tests were used for two group comparisons. Wilcoxon signed-ranked test was used for matched analysis, and Mann-Whitney test was used for two independent group comparisons. Chi-square test was used for comparison of ratios between two groups. Spearman's rank correlation was used to determine the relationship between variables. A $p$-value of $<0.05$ was considered significant. Cross-tabulation was used to calculate the sensitivities and specificities of diagnostic tests.

\section{Ethical considerations}

The study was evaluated and approved by the Research, Ethics and Publications Committee at the Dr. George Mukhari Hospital, University of Limpopo, South Africa (2003) and the Regional Committee for Ethics in Medical Research in Bergen, Norway (2003, REK Vest nr.185.02). 
All the patients received written and verbal information of the study and all gave informed written consent.

\section{Results}

\section{Patient characteristics}

Table 2 shows the demographic and laboratory characteristics of the 41 patients enrolled in the study. Case based information is provided in Additional file 1. Thirty-two (78\%), were classified as pleural TB cases based on the composite reference standard, and nine as non-TB cases. Thirteen patients had culture confirmed pleural TB, 26 (81\%) were HIV pleural TB co-infected, and 64\% of these had $<100 \mathrm{CD} 4+\mathrm{T}$ cells/microL. The median ADA level was $62 \mathrm{U} / \mathrm{L}$. Among non-TB cases, 5 (56\%) were HIV positive and median ADA levels were $15 \mathrm{U} / \mathrm{L}$. Seven of the study participants had a history of previous TB with anti-tuberculous treatment finished more than 1 year before study inclusion.

\section{Culture, PCR and mycobacterial antigens in the pleural fluid mononuclear cells according to the TB and HIV status}

Among the HIV pleural TB co-infected, the proportion of culture positive cases was significantly higher as compared to the HIV-negative pleural TB cases (50\% versus $0 \%$, respectively), while the proportion of AFB microscopy, nested-PCR and real-time PCR was not different (Table 3). Among the non-TB cases, there was no difference between HIV positive and HIV negative cases, except for a higher number of positive for a combination of culture or nested-PCR or any antigen in the HIV positive group (Table 3 ).

Mycobacterial antigens were observed as intracellular granular staining in the cytoplasm of pleural fluid mononuclear cells (Fig. 2). There was no difference in the proportion of mycobacterial antigen positive cases or load of any antigens between HIV positive and HIV negative pleural TB cases (Table 3). The load of individual antigens varied among pleural TB cases. Heterogeneous antigens were the most abundant (Fig. 3) and were higher as compared to LAM $(p=0.04)$ and secreted antigen $(p=0.02)$ (Fig. 3). The levels of antigens had a significant positive correlation with each other, except between heterogeneous mycobacterial antigens and cell wall antigen (Table 4). Interestingly, culture had a tendency towards negative correlation with all antigens, but the association was not statistically significant (Table 4).

Table 2 Demographic and laboratory characteristics of patients

\begin{tabular}{|c|c|}
\hline Characteristics $\boldsymbol{n}=41$ & Number \\
\hline \multicolumn{2}{|l|}{ Gender } \\
\hline Females & $16(39 \%)$ \\
\hline Males & $25(61 \%)$ \\
\hline Age, median (range) & $36(19-69)$ \\
\hline Pleural TB cases & $32(78 \%)$ \\
\hline \multicolumn{2}{|l|}{ Diagnosis based on } \\
\hline Culture & $13(41 \%)$ \\
\hline AFB microscopy,+ ADA $>30$ and clinical evidence & $1(3 \%)$ \\
\hline ADA $>30$ and clinical evidence & $17(53 \%)$ \\
\hline Clinical evidence only ${ }^{\mathrm{b}}$ & $1(3 \%)$ \\
\hline HIV positive & $26(81 \%)$ \\
\hline $\mathrm{CD} 4+\mathrm{T}$ cell count $\mathrm{HIV+}$, (n) median $(\text { range })^{\mathrm{a}}$ & (22) $80(7-328)$ \\
\hline CD4+ $\mathrm{T}$ cell count $>100$ cells/microL & $8(36 \%)$ \\
\hline CD4+ T cell count $<100$ cells/microL & $14(64 \%)$ \\
\hline ADA levels $U / L(n)$ median (range) ${ }^{a}$ & (29) $62(4-200)$ \\
\hline Non-TB cases & $9(22 \%)$ \\
\hline Malignancy & $3(33 \%)$ \\
\hline Another non-TB condition ${ }^{c}$ & $6(67 \%)$ \\
\hline HIV positive & $5(56 \%)$ \\
\hline CD4+ T cell count HIV+, (n) median (range) ${ }^{a}$ & (4) $119(49-375)$ \\
\hline CD4+ $\mathrm{T}$ cell count $>100$ cells/microL & $3(75 \%)$ \\
\hline CD4+ T cell count $<100$ cells/microL & $1(25 \%)$ \\
\hline ADA levels $U / L(n)$ median (range)a & (9) $15(1-29)$ \\
\hline
\end{tabular}

$n$ number, ${ }^{a}$ results were not available for some patients

${ }^{\mathrm{b}} \mathrm{ADA}$ level just below cutoff

'Pleural effusion of other known etiology such as congestive cardiac failure or para-pneumonic effusion 
Table 3 Results of various procedures on pleural fluid mononuclear cells

\begin{tabular}{|c|c|c|c|c|}
\hline & \multicolumn{2}{|c|}{ TB cases $(\boldsymbol{n}=32)$} & \multicolumn{2}{|c|}{ Non-TB $(\boldsymbol{n}=9)$} \\
\hline & $\mathrm{HIV}+(\boldsymbol{n}=26)$ & HIV- $(\boldsymbol{n}=6)$ & $\mathrm{HIV}+(\boldsymbol{n}=5)$ & HIV- $(\boldsymbol{n}=4)$ \\
\hline AFB microscopy+ n (\%) & $3(12 \%)$ & $1(17 \%)$ & $0(0 \%)$ & $0(0 \%)$ \\
\hline Culture+ n (\%) & $13(50 \%)$ & $0(0 \%)^{*}$ & $0(0 \%)$ & $0(0 \%)$ \\
\hline Nested PCR+ n (\%) & $15(58 \%)$ & $2(33 \%)$ & $1(20 \%)$ & $0(0 \%)$ \\
\hline Real-time PCR+ n (\%) & $2(8 \%)$ & $0(0 \%)$ & $0(0 \%)$ & $0(0 \%)$ \\
\hline \multicolumn{5}{|l|}{ Mycobacterial antigens by immunocytochemistry } \\
\hline Heterogeneous antigens+ n (\%) & $11(42 \%)$ & $2(33 \%)$ & $4(80 \%)$ & $0(0 \%)$ \\
\hline Cell wall antigen+ n (\%) & $10(38 \%)$ & $2(33 \%)$ & $1(20 \%)$ & $1(25 \%)$ \\
\hline $\mathrm{LAM}+\mathrm{n}(\%)$ & $13(50 \%)$ & $2(33 \%)$ & $0(0 \%)$ & $0(0 \%)$ \\
\hline Secreted antigen+ n (\%) & $9(35 \%)$ & $3(50 \%)$ & $2(40 \%)$ & $0(0 \%)$ \\
\hline Any antigen+ n (\%) & $19(73 \%)$ & $4(67 \%)$ & $4(80 \%)$ & $1(25 \%)$ \\
\hline LAM or secreted antigen $+n(\%)$ & $14(54 \%)$ & $4(67 \%)$ & $2(40 \%)$ & $0(0 \%)$ \\
\hline LAM and secreted antigen+ $\mathrm{n}(\%)$ & $8(31 \%)$ & $1(17 \%)$ & $0(0 \%)$ & $0(0 \%)$ \\
\hline Heterogeneous antigens stained cells/100 fields median (range) & $0(0-348)$ & $0(0-66)$ & $8(0-31)$ & $0(0-0)$ \\
\hline Cell wall antigen stained cells/100 fields median (range) & $0(0-130)$ & $0(0-19)$ & $0(0-1)$ & $0(0-1)$ \\
\hline LAM, stained cells/100 fields median (range) & $0.5(0-33)$ & $0(0-12)$ & $0(0-0)$ & $0(0-0)$ \\
\hline Secreted antigen stained cells/100 fields median (range) & $0(0-72)$ & $2(0-12)$ & $0(0-5)$ & $0(0-0)$ \\
\hline \multicolumn{5}{|l|}{ Combinations of antigens and other diagnostic tests } \\
\hline Culture and/or n-PCR and/or any antigen+ $\mathrm{n}(\%)$ & $23(89 \%)$ & $5(83 \%)$ & $5(100 \%)^{*}$ & $1(25 \%)$ \\
\hline Culture and/or n-PCR and/or LAM n (\%) & $21(81 \%)$ & $4(67 \%)$ & $1(20 \%)$ & $0(0 \%)$ \\
\hline
\end{tabular}

${ }^{*}$ significant difference between HIV positive and HIV negative by Pearson chi-square, $p$ value $<0.05$

Association of mycobacterial DNA load with culture, AFB microscopy and the mycobacterial antigens was also studied. Cases with higher DNA load had higher number of culture positive $(p=0.06)$, microscopy positive $(p=0.07)$ and cell wall antigen positive $(p=0.007)$ results as compared to those with lower DNA load (Table 5). Figure 4 shows the load of various antigens among cases with higher and lower DNA load. The load of cell wall antigen was higher in the cases with higher DNA load $(p=0.02)$, while there was no difference in the load of any of the other mycobacterial antigens studied (Fig. 4). Additional file 1 provides case-based information.

\section{Association of CD4+ T-cell count with the mycobacterial antigens and bacterial load in pleural TB patients}

Pleural TB cases with CD4+ T-cell counts $<100$ had higher number of culture positive cases as compared to cases with CD4+ T-cell counts $>100(p=0.07)($ Table 5), indicating higher viable bacterial load. There was a significant negative correlation between the CD4+ T-cell counts and culture $(p=0.006)$ (Table 4$)$. The number of cases positive for cell wall antigen $(p=0.003)$ and secreted antigen $(p=0.04)$ were also higher in those with CD4+ T cell count $<100$ (Table 5). The load of individual antigens was higher among cases with CD4+ T-cell count $<100$ as compared to those with $\mathrm{CD} 4+\mathrm{T}$-cell count $>100$. The only statistically significant difference was seen for cell wall antigen $(p=0.01)$, where this antigen was not detected in cases with higher CD4+ T-cell counts (Fig. 5). There was a trend towards negative correlation between $\mathrm{CD} 4+\mathrm{T}$-cell counts and the mycobacterial antigens, though without statistical significance (Table 4). Additional file 1 provides case-based information.

\section{Performance of various mycobacterial antigens as diagnostic test}

Using the composite reference standard, sensitivity and specificity of the individual antigens to diagnose pleural TB was between 38 and $47 \%$ and $56-100 \%$ respectively (Table 6). LAM was the most frequently detected antigen (47\%) and was not detected in any of the non-TB cases. When using culture or the combination of culture and nested-PCR as reference standard, the sensitivity of the individual antigens was, in general, higher. Except for heterogenous antigens, the specificity, was lower as compared to the composite reference standard.

Among rapid tests, the sensitivity of antigen detection was better than the AFB microscopy and real-time PCR, and very close to the nested-PCR. The sensitivity of culture was $41 \%$. By using a composite antigen detection approach based on the detection of any of the four mycobacterial antigens, the sensitivity improved to $72 \%$, 


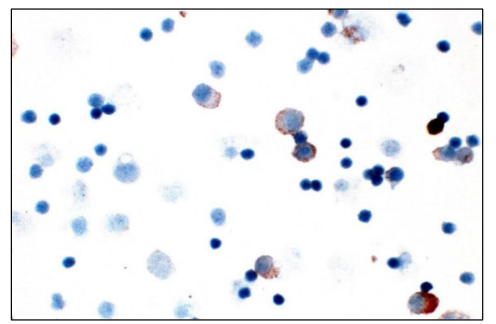

Heterogenous antigens $x 40$

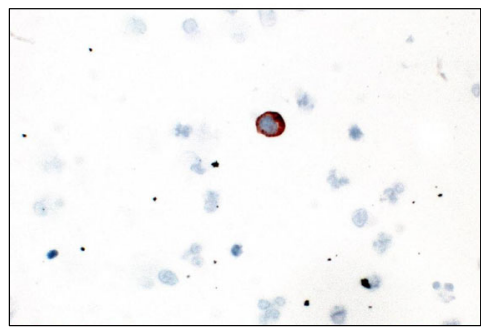

LAM $\times 40$

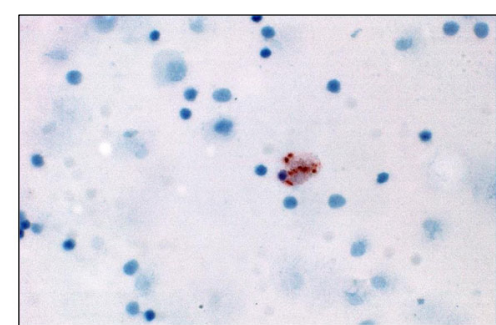

Cell wall antigens $x 40$

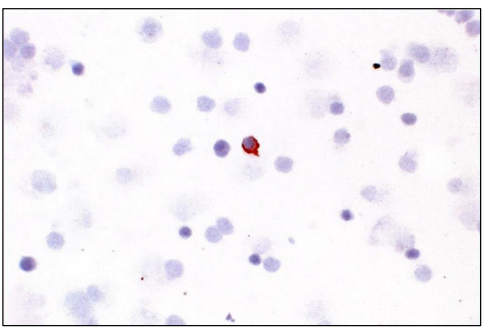

Secreted antigen $x 40$

Fig. 2 Cell smears from the mononuclear cells from tuberculous pleural effusions showing the staining pattern of mycobacterial antigens as detected by immunocytochemical staining. Staining pattern is intracellular granular in the cytoplasm of pleural fluid mononuclear cells

which was better than all the other tests, although the specificity was reduced to $44 \%$ (Table 6 ).

Using culture as a reference standard, the sensitivity of the individual antigens was better than AFB microscopy and real-time PCR, but lower than the nested-PCR. By using a combination of culture and nested-PCR as reference standard, the sensitivity of antigen detection was much better than the AFB microscopy and real-time PCR (Table 6).

\section{Head-to-head comparison of various diagnostic methods} As the different diagnostic tests were positive in different cases, a head-to-head comparison of all tests was also performed to show that combination of various tests gives a better diagnostic yield as compared to a single test (Table 7). Among the 23 nested-PCR negative cases, 10 more cases were positive with combination of secreted antigen and LAM, and 15 more cases with combination of all antigens. A combination of culture, nested-PCR, and mycobacterial antigens was positive in $28(88 \%)$ of pleural TB cases, indicating added value of combining various diagnostic tests.

\section{Discussion}

In this study, we have shown that PFMC from tuberculous pleural effusions detain secreted and cell wall associated mycobacterial antigens. HIV coinfection had an impact on the bacterial burden, shown by a significantly higher number of culture positive effusion in the HIV pleural TB co-infected group. In addition, in the HIV

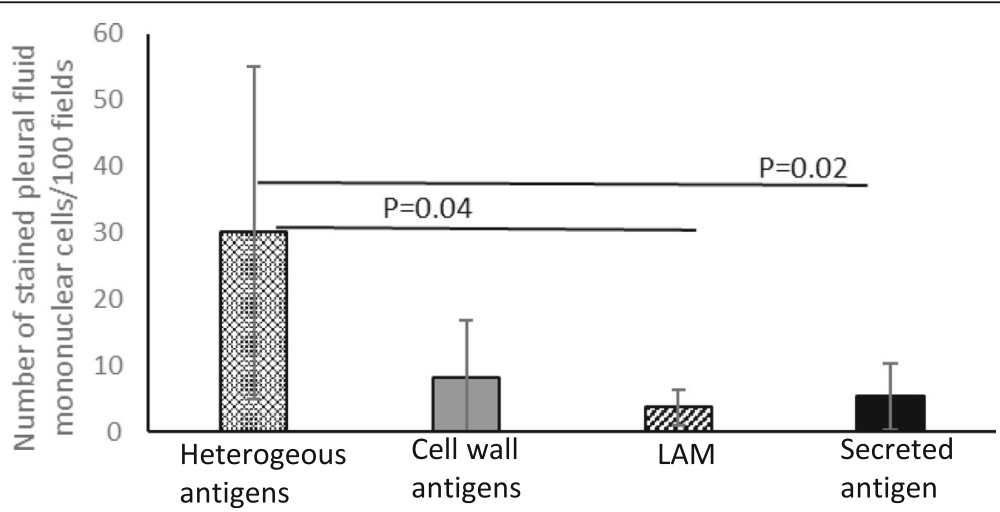

Fig. 3 The mycobacterial antigen load among pleural TB cases $(n=32)$ measured by the number of stained pleural fluid mononuclear cells per 100 fields. Wilcoxon Signed Ranks Test for paired samples was used for comparisons 
Table 4 Relationship between culture, nested-PCR, bacterial DNA load, CD4+ T cell count and levels of mycobacterial antigens in the tuberculous pleural fluid mononuclear cells based on Spearman's rank correlation. The values shown are the correlation coefficients

\begin{tabular}{|c|c|c|c|c|c|c|}
\hline & Culture & DNA load & Heterogeneous antigens & Cell wall antigen & LAM & Secreted antigen \\
\hline DNA load & $0.467^{b}$ & & & & & \\
\hline Heterogeneous antigens & 0.198 & 0.155 & & & & \\
\hline Cell wall antigen & -0.067 & 0.270 & 0.259 & & & \\
\hline LAM & 0.217 & 0.079 & $0.442^{\mathrm{a}}$ & $0.370^{\mathrm{a}}$ & & \\
\hline Secreted antigen & 0.032 & 0.088 & $0.625^{b}$ & $0.663^{b}$ & $0.439^{a}$ & \\
\hline$N-P C R$ & $-0.394^{\mathrm{a}}$ & $-0.938^{b}$ & -0.236 & -0.117 & -0.110 & -0.055 \\
\hline CD4+ T cell count & $-0.507^{b}$ & -0.341 & -0.184 & -0.272 & -0.050 & -0.122 \\
\hline
\end{tabular}

${ }^{a}$ Correlation is significant at the 0.05 level (2-tailed), ${ }^{b}$ Correlation is significant at the 0.01 level (2-tailed). N-PCR Nested PCR DNA load is measured based on the number of positives among triplets from each case

pleural TB co-infected group, the cases with low CD4+ $\mathrm{T}$ cell count had a higher number of culture positives and higher loads of cell wall antigen and secreted antigen. These findings imply that low CD4+ T-cell counts impair the host ability to clear the infection, resulting in persistence of bacilli and accumulation of mycobacterial antigens. Earlier studies have shown that HIV coinfected pulmonary TB patients with lower CD4+ T-cell count have detectable LAM in the urine, indicating higher burden of LAM with CD4 + T-cell depletion [18]. In our study, the LAM was not significantly higher expressed in the HIV cases with low CD4+ T-cell count, while cell wall antigen and secreted antigen was higher.
These differences may be due to the differential accumulation of various mycobacterial antigens at different sites of infection as shown earlier [17], due to the relatively small sample size, or due to different affinities and specificities of the primary antibodies.

Mycobacterial antigens are shown to accumulate in the infected tissues $[17,19-25,31]$. As antigens accumulate as a result of bacterial replication, one would expect a positive correlation between presence of viable bacteria and the antigens. However, a tendency towards negative correlation was seen with cell wall antigens, though the relationship was not statistically significant. This could be due to the persistence of antigens in the infected

Table 5 Relationship of CD4+ T cell count in HIV-pleural TB co-infected ( $n=22, C D 4+$ T cell count not available for four patients), and the mycobacterial DNA load in all nested-PCR positive patients $(n=18)$ with AFB microscopy, culture and the mycobacterial antigens by Pearson chi-square test

\begin{tabular}{|c|c|c|c|c|c|c|}
\hline & CD4 $>100$ & $C D 4<100$ & $p$-value & DNA low ${ }^{a}$ & DNA high $^{a}$ & $p$-value \\
\hline culture+ & 2 & 9 & 0.07 & 2 & 8 & 0.06 \\
\hline culture- & 6 & 5 & & 5 & 3 & \\
\hline Microscopy + & 0 & 3 & 0.15 & 0 & 4 & 0.07 \\
\hline Microscopy - & 8 & 11 & & 7 & 7 & \\
\hline Cell wall antigen+ & 0 & 9 & 0.003 & 0 & 7 & 0.007 \\
\hline Cell wall antigen- & 8 & 5 & & 7 & 4 & \\
\hline Heterogeneous antigens+ & 2 & 8 & 0.14 & 4 & 5 & 0.62 \\
\hline Heterogeneous antigens- & 6 & 6 & & 3 & 6 & \\
\hline LAM+ & 3 & 8 & 0.37 & 4 & 5 & 0.62 \\
\hline LAM- & 3 & 6 & & 3 & 6 & \\
\hline secreted antigen+ & 1 & 8 & 0.04 & 2 & 5 & 0.47 \\
\hline secreted antigen- & 7 & 6 & & 5 & 6 & \\
\hline N-PCR+ & 3 & 9 & 0.22 & & & \\
\hline N-PCR- & 5 & 5 & & & & \\
\hline RT-PCR+ & 0 & 2 & 0.26 & 0 & 2 & 0.23 \\
\hline RT-PCR- & 8 & 12 & & 7 & 9 & \\
\hline
\end{tabular}

$N-P C R$ Nested PCR, RT-PCR Real time PCR

${ }^{a}$ DNA load is based on the number of positives among triplets from each case, low $=1 / 3$, high $=3 / 3$ positive 


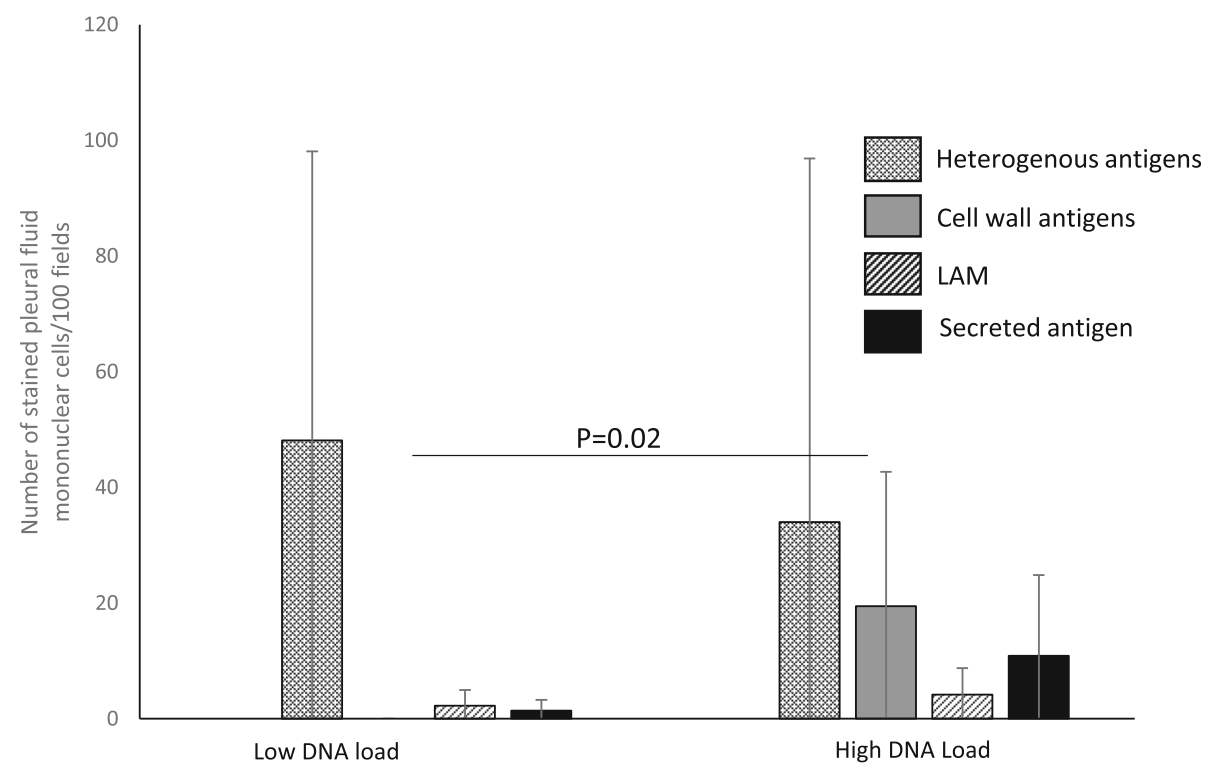

Fig. 4 Difference in the mycobacterial antigen load among cases with higher and lower DNA load $(n=18)$. Mycobacterial DNA load is categorized based on the number of positives with nested-PCR among the triplets from each specimen. Mann-Whitney test was used for comparisons

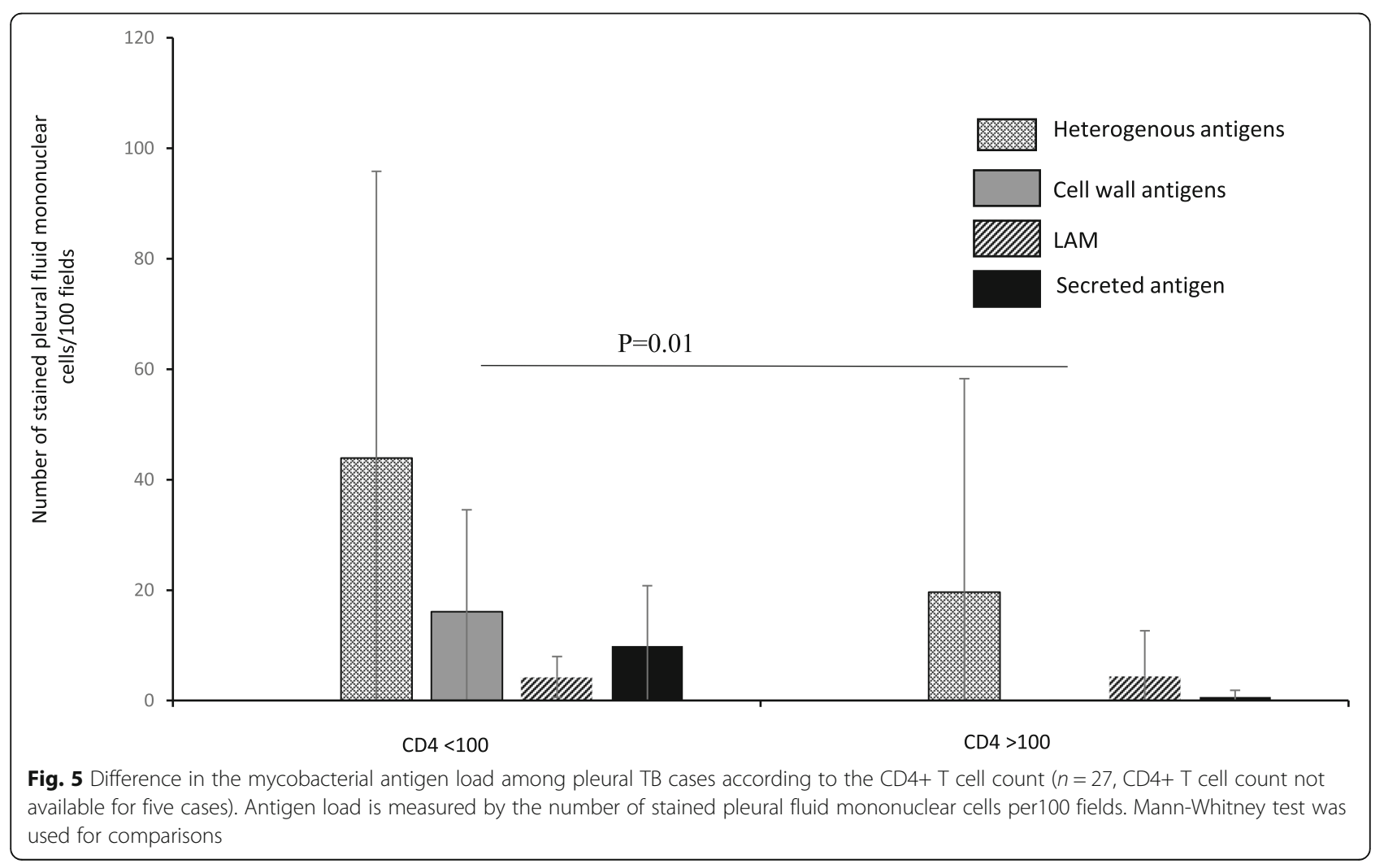


Table 6 Diagnostic validity of different tests performed on pleural fluid samples by using three reference standards

\begin{tabular}{|c|c|c|c|c|c|c|}
\hline & \multicolumn{2}{|c|}{ CRS } & \multicolumn{2}{|c|}{ Culture } & \multicolumn{2}{|c|}{ Culture \& N-PCR } \\
\hline & SN & SP & SN & SP & SN & SP \\
\hline Culture & 41 & 100 & & & & \\
\hline Nested-PCR & 53 & 89 & 77 & 71 & & \\
\hline Real-time PCR & 6 & 100 & 15 & 100 & 12 & 100 \\
\hline AFB Microscopy & 12 & 100 & 23 & 96 & 23 & 100 \\
\hline \multicolumn{7}{|l|}{ Mycobacterial antigens } \\
\hline Cell wall antigen & 38 & 78 & 31 & 64 & 41 & 71 \\
\hline LAM & 47 & 100 & 54 & 71 & 53 & 75 \\
\hline Heterogeneous antigens & 41 & 56 & 54 & 64 & 47 & 62 \\
\hline Secreted antigen & 38 & 78 & 39 & 68 & 35 & 67 \\
\hline Secreted antigen or LAM & 56 & 78 & 54 & 54 & 59 & 58 \\
\hline Any 4 antigens & 72 & 44 & 69 & 32 & 76 & 37 \\
\hline Culture, nested-PCR or any antigen & 88 & 33 & & & & \\
\hline Culture, nested-PCR or LAM & 78 & 89 & & & & \\
\hline
\end{tabular}

CRS Composite reference standard, SN Sensitivity, SP Specificity

cells, while bacteria are killed with the advent of an apt immune response, as shown previously in the murine pulmonary TB lesions [31]. These accumulated antigens could play a role in the persistence of inflammation and chronicity of disease. This may explain the low yield of culture in pleural TB, where pathology is sustained by antigens rather than viable bacteria, underlining the importance of measuring antigens in culture negative cases when TB diagnosis is uncertain.

The secreted antigen MPT64 constitutes a small fraction of the secreted antigens in in vitro culture filtrates [29]. On the other hand, in vivo it is detectable in quantities comparable to other major cell-wall associated antigens. This is most probably due to accumulation of this antigen in the infected cells. Our previous study on pleural biopsies from the same hospital have shown that this antigen is detectable in $80 \%$ of the pleural TB biopsies, while only $20 \%$ of these biopsies were positive with culture [19]. In the present study, this antigen was detected in $38 \%$ of cases, which is much lower as compared to other studies using the same antibody $[20,23,25]$. This could be due to the isolation and storage of cells before staining in this study. The freeze-thaw process could have resulted in the degradation of antigen. In other studies, the smears were prepared from fresh specimens which were fixed immediately.

LAM is a promising mycobacterial antigen detection test for pulmonary TB in HIV TB co-infected patients [18]. In our study, LAM was the most abundant antigen in the PFMC and was detectable in $47 \%$ of pleural TB cases. By combining detection of secreted antigen or LAM, $56 \%$ of cases were detected, which is higher than other tests used in TB diagnostics. The specificity of this combination was $78 \%$ compared with $100 \%$ for detection of LAM alone. Thus, antigen detection by immunocytochemistry is a robust and rapid test and may assist the clinical decision to start treatment before culture results are available. This would reduce diagnostic delay and curb empirical over-treatment in the absence of bacterial confirmation. Unlike PCR, this method is not sensitive to contamination and can be implemented in a basic pathology lab in high TB endemic settings, without the need for high tech equipment. However, this needs to be evaluated on a larger sample to ensure reproducibility.

One disadvantage of the antigen detection by immunocytochemistry was the number of false positive tests. This could be caused by non-specific binding of the antibodies. However, some results could be true positives, as implied by the higher false positivity in the HIV positive cases. TB is a common co-morbidity in high TB endemic settings, and due to atypical clinical presentation of TB in HIV co-infected patients, some cases could be misdiagnosed in the absence of bacteriological confirmation.

Pleural TB is known to be a paucibacillary disease and this is also confirmed in our study, as only $12 \%$ of the cases were positive with direct microscopy, $41 \%$ with culture, and only $6 \%$ with real-time PCR. The low sensitivity of real-time PCR is similar to the results of Xpert MTB/RIF assay on pleural effusions [20]. WHO has not recommended the Xpert MTB/RIF assay for diagnosis of pleural effusions due to low sensitivity [32]. Nested-PCR was positive in $53 \%$ cases. However, this PCR is not suitable for routine use in high TB endemic setting due to risk of contamination. Even though there was positive correlation between the cases positive with culture and DNA load, there was a negative correlation between culture positivity and nested-PCR. This finding implies that 


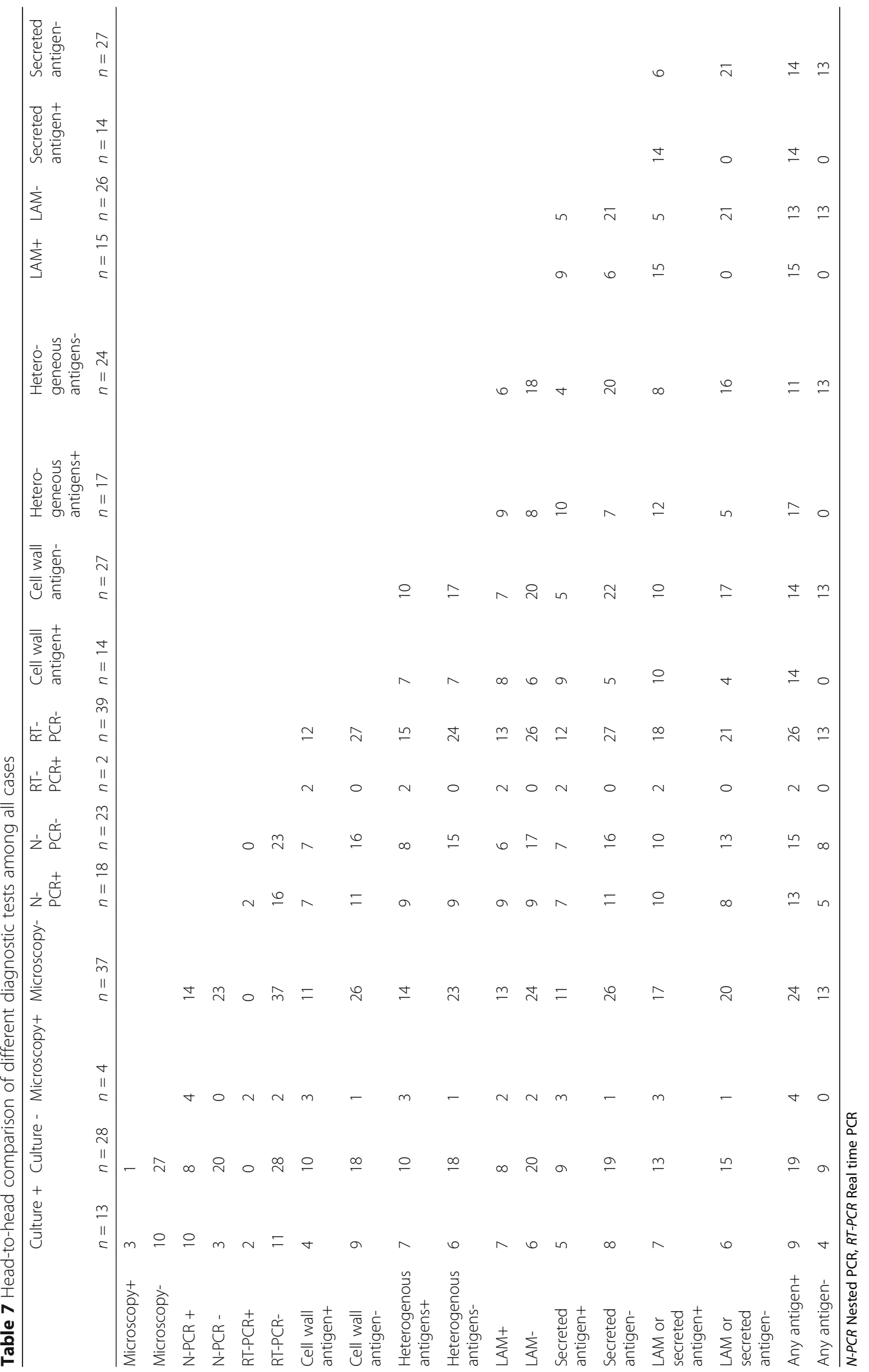


DNA might persist in the tissues, even if the bacilli are killed as shown previously in murine tissues [33].

\section{Conclusion}

Mycobacterial antigens were detectable in PFMC from tuberculous pleural effusions by immunocytochemistry. There was no direct correlation between antigens and culture, implying that antigens persist in the infected tissues despite clearance of bacilli. More cases can be diagnosed by combination of antigen detection and culture. A combination of LAM and secreted antigen could diagnose more cases of pleural TB as compared to all the routine tests. This immunocytochemistry-based method is rapid and robust, and unlike PCR, it is not sensitive to contamination. Hence, it can contribute to the timely management of pleural TB cases in high TB and HIV endemic settings. Further studies are required to test the reproducibility of the test.

\section{Supplementary information}

Supplementary information accompanies this paper at https://doi.org/10. 1186/s12879-020-05165-6.

Additional file 1 .

\section{Abbreviations}

ADA: Adenosine deaminase activity; AFB: Acid fast bacilli; BCG: Bacille Calmette- Guèrin; FCS: Fetal calf serum; LAM: Lipoarabinomannan; PCR: Polymerase Chain Reaction; PFMC: Pleural fluid mononuclear cells; TB: Tuberculosis

\section{Acknowledgements}

We thank Professor Harald G. Wiker for his contribution in the development of polyclonal antibodies, Dr. George Mukhari Hospital, Ga-Rankuwa, Pretoria South Africa for supporting the study.

\section{Authors' contributions}

TM has participated in design of the study, analysis and interpretation of data and drafting of the manuscript. IW has done the experimental work, analysis and interpretation of data and revision of the manuscript. SP has performed the real-time PCR and revision of the manuscript. KB has included the patients, collected, and processed the samples and revised the manuscript. $\mathrm{AH}$ has participated in design of the original study, inclusion of patients and revision of the manuscript. AMDR was Principal Investigator for the original study, participated in funding acquisition, initiation and design of the study, interpretation of data and revision of the manuscript. All authors read and approved the final manuscript.

\section{Funding}

The study was funded by grants from Haukeland University Hospital (Helse Vest RHF funding) and the University of Bergen.

\section{Availability of data and materials}

The datasets used and/or analyzed during the current study are provided as an additional file.

\section{Ethics approval and consent to participate}

The study was evaluated and approved by the Research, Ethics and Publications Committee at the Dr. George Mukhari Hospital, University of Limpopo, South Africa (2003) and the Regional Committee for Ethics in Medical Research in Bergen, Norway (2003, REK Vest nr.185.02). All the patients received written and verbal information of the study and all gave written informed consent.
Consent for publication

Not applicable.

\section{Competing interests}

The authors declare that they have no competing interests.

\section{Author details}

${ }^{1}$ Centre for International Health, Department of Global Public Health and Primary Care, University of Bergen, P.O. box 7804, N-5020 Bergen, Norway. ${ }^{2}$ Department of Thoracic Medicine, Haukeland University Hospital, Bergen, Norway. ${ }^{3}$ Department of Internal Medicine, Haukeland University Hospital, Bergen, Norway. ${ }^{4}$ Department of Microbiological Pathology, Medunsa Campus, University of Limpopo, Mankweng, South Africa. ${ }^{5}$ Department of Pathology and Laboratory Medicine, King Abdullah bin Abdulaziz University Hospital, Princess Noura bint Abdulrahman University, Riyadh, Saudi Arabia. ${ }^{6}$ Department of Respiratory Medicine, Oslo University Hospital, Rikshospitalet, Oslo, Norway. ${ }^{7}$ Pathcare - Vermaak \& Partners Pathologists and Department of Medical Microbiology, University of Pretoria, Pretoria, South Africa.

${ }^{8}$ Department of Infectious Diseases, Oslo University Hospital, Oslo, Norway. ${ }^{9}$ Institute of Clinical Medicine, University of Oslo, Oslo, Norway. ${ }^{10}$ Department of Clinical Science, University of Bergen, Bergen, Norway.

Received: 6 December 2019 Accepted: 17 June 2020 Published online: 01 July 2020

\section{References}

1. Global tuberculosis report. Geneva: World Health Organization; 2019. Available at: https://www.who.int/tb/publications/global_report/en/. Accessed May 2020.

2. Harries AD, Nyangulu DS, Kangombe C, Ndalama D, Wirima JJ, Salaniponi FM, et al. The scourge of HIV-related tuberculosis: a cohort study in a district general hospital in Malawi. Ann Trop Med Parasitol. 1997;91(7):771-6.

3. Jones BE, Young SM, Antoniskis D, Davidson PT, Kramer F, Barnes PF. Relationship of the manifestations of tuberculosis to CD4 cell counts in patients with human immunodeficiency virus infection. Am Rev Respir Dis. 1993;148(5):1292-7.

4. Vorster MJ, Allwood BW, Diacon AH, Koegelenberg CF. Tuberculous pleural effusions: advances and controversies. J Thorac Dis. 2015;7(6):981-91.

5. Diacon AH, Van de Wal BW, Wyser C, Smedema JP, Bezuidenhout J, Bolliger $C T$, et al. Diagnostic tools in tuberculous pleurisy: a direct comparative study. Eur Respir J. 2003;22(4):589-91.

6. $\quad$ Light RW. Update on tuberculous pleural effusion. Respirology. 2010;15(3): 451-8.

7. Casalini AG, Cusmano F, Sverzellati N, Mori PA, Majori M. An undiagnosed pleural effusion with surprising consequences. Respir Med Case Rep. 2017; 22:53-6.

8. Roper $\mathrm{WH}$, Waring JJ. Primary serofibrinous pleural effusion in military personnel. Am Rev Tuberc. 1955;71(5):616-34.

9. Koh WJ. Progression of Tuberculous pleurisy: from a lymphocytepredominant free-flowing effusion to a neutrophil-predominant Loculated effusion. Tuberc Respir Dis (Seoul). 2017;80(1):90-2.

10. Ruan SY, Chuang YC, Wang JY, Lin JW, Chien JY, Huang CT, et al. Revisiting tuberculous pleurisy: pleural fluid characteristics and diagnostic yield of mycobacterial culture in an endemic area. Thorax. 2012;67(9):822-7.

11. Shaw JA, Irusen EM, Diacon AH, Koegelenberg CF. Pleural tuberculosis: A concise clinical review. Clin Respir J. 2018;12(5):1779-86.

12. Emile JF, Patey N, Altare F, Lamhamedi S, Jouanguy E, Boman F, et al. Correlation of granuloma structure with clinical outcome defines two types of idiopathic disseminated BCG infection. J Pathol. 1997;181(1):25-30.

13. Idell S. Evaluation of perplexing pleural effusions. Contemp Intern Med. 1994;6(12):31-9.

14. Barbolini G, Bisetti A, Colizzi V, Damiani G, Migaldi M, Vismara D. Immunohistologic analysis of mycobacterial antigens by monoclonal antibodies in tuberculosis and mycobacteriosis. Hum Pathol. 1989;20(11): 1078-83.

15. Fenhalls G, Stevens L, Moses L, Bezuidenhout J, Betts JC, Helden Pv P, et al. In situ detection of Mycobacterium tuberculosis transcripts in human lung granulomas reveals differential gene expression in necrotic lesions. Infect Immun. 2002;70(11):6330-8.

16. Goel MM, Budhwar P. Immunohistochemical localization of mycobacterium tuberculosis complex antigen with antibody to $38 \mathrm{kDa}$ antigen versus Ziehl 
Neelsen staining in tissue granulomas of extrapulmonary tuberculosis. Indian J Tuberc. 2007;54(1):24-9.

17. Mustafa T, Leversen NA, Sviland L, Wiker HG. Differential in vivo expression of mycobacterial antigens in Mycobacterium tuberculosis infected lungs and lymph node tissues. BMC Infect Dis. 2014;14:535.

18. Lawn SD. Point-of-care detection of lipoarabinomannan (LAM) in urine for diagnosis of HIV-associated tuberculosis: a state of the art review. BMC Infect Dis. 2012;12:103.

19. Baba K, Dyrhol-Riise AM, Sviland L, Langeland N, Hoosen AA, Wiker HG, et al. Rapid and specific diagnosis of tuberculous pleuritis with immunohistochemistry by detecting Mycobacterium tuberculosis complex specific antigen MPT64 in patients from a HIV endemic area. Appl Immunohistochem Mol Morphol. 2008;16(6):554-61.

20. Jorstad MD, Marijani M, Dyrhol-Riise AM, Sviland L, Mustafa T. MPT64 antigen detection test improves routine diagnosis of extrapulmonary tuberculosis in a low-resource setting: a study from the tertiary care hospital in Zanzibar. PLoS One. 2018;13(5):e0196723.

21. Mustafa T, Wiker HG, Mfinanga SG, Morkve O, Sviland L. Immunohistochemistry using a Mycobacterium tuberculosis complex specific antibody for improved diagnosis of tuberculous lymphadenitis. Mod Pathol. 2006;19(12):1606-14.

22. Purohit MR, Mustafa T, Wiker HG, Morkve O, Sviland L. Immunohistochemical diagnosis of abdominal and lymph node tuberculosis by detecting Mycobacterium tuberculosis complex specific antigen MPT64. Diagn Pathol. 2007;2:36.

23. Purohit MR, Mustafa T, Wiker HG, Sviland L. Rapid diagnosis of tuberculosis in aspirate, effusions, and cerebrospinal fluid by immunocytochemical detection of Mycobacterium tuberculosis complex specific antigen MPT64. Diagn Cytopathol. 2012;40(9):782-91.

24. Purohit MR, Sviland L, Wiker H, Mustafa T. Rapid and specific diagnosis of Extrapulmonary tuberculosis by Immunostaining of tissues and aspirates with anti-MPT64. Appl Immunohistochem Mol Morphol. 2017;25(4):282-8.

25. Tadele A, Beyene D, Hussein J, Gemechu T, Birhanu A, Mustafa T, et al. Immunocytochemical detection of Mycobacterium tuberculosis complex specific antigen, MPT64, improves diagnosis of tuberculous lymphadenitis and tuberculous pleuritis. BMC Infect Dis. 2014;14:585.

26. Baba K, Sornes S, Hoosen AA, Lekabe JM, Mpe MJ, Langeland N, et al. Evaluation of immune responses in HIV infected patients with pleural tuberculosis by the QuantiFERON TB-gold interferon-gamma assay. BMC Infect Dis. 2008;8:35.

27. Blake J, Berman P. The use of adenosine deaminase assays in the diagnosis of tuberculosis. S Afr Med J. 1982;62(1):19-21.

28. Baba K, Hoosen AA, Langeland N, Dyrhol-Riise AM. Adenosine deaminase activity is a sensitive marker for the diagnosis of tuberculous pleuritis in patients with very low CD4 counts. PLoS One. 2008;3(7):e2788.

29. Nagai S, Wiker HG, Harboe M, Kinomoto M. Isolation and partial characterization of major protein antigens in the culture fluid of Mycobacterium tuberculosis. Infect Immun. 1991;59(1):372-82.

30. Baba K, Pathak S, Sviland L, Langeland N, Hoosen AA, Asjo B, et al. Real-time quantitative $P C R$ in the diagnosis of tuberculosis in formalin-fixed paraffinembedded pleural tissue in patients from a high HIV endemic area. Diagn Mol Pathol. 2008;17(2):112-7.

31. Mustafa T, Phyu S, Nilsen R, Jonsson R, Bjune G. A mouse model for slowly progressive primary tuberculosis. Scand J Immunol. 1999;50(2):127-36.

32. Automated real-time nucleic acid amplification technology for rapid and simultaneous detection of tuberculosis and rifampicin resistance: Xpert MTB/RIF assay for the diagnosis of pulmonary and extrapulmonary TB in adults and children. Policy update. World Health Organization; 2013. Available at: https://www.ncbi.nlm.nih.gov/books/NBK258608/. Accessed June 2020.

33. Pathak $\mathrm{S}$, Awuh JA, Leversen NA, Flo TH, Asjo B. Counting mycobacteria in infected human cells and mouse tissue: a comparison between GPCR and CFU. PLoS One. 2012;7(4):e34931.

\section{Publisher's Note}

Springer Nature remains neutral with regard to jurisdictional claims in published maps and institutional affiliations.

Ready to submit your research? Choose BMC and benefit from:

- fast, convenient online submission

- thorough peer review by experienced researchers in your field

- rapid publication on acceptance

- support for research data, including large and complex data types

- gold Open Access which fosters wider collaboration and increased citations

- maximum visibility for your research: over $100 \mathrm{M}$ website views per year

At BMC, research is always in progress.

Learn more biomedcentral.com/submissions 